\title{
Development and optimization of industrial scale chromatography for use in manufacturing
}

\author{
A.M. Katti ${ }^{1}$ and P. Jagland ${ }^{2}$ \\ ${ }^{1}$ NaPro BioTherapeutics Inc., Boulder, CO 80301, USA \\ ${ }^{2}$ Eka Chemicals, Bohus, S-445 80, Sweden
}

\begin{abstract}
The selection of design parameters and the optimization of operating parameters to minimize the total cost for the purpose of improving the economics of chromatographic operations for manufacturing is a challenging problem. This paper uses a mathematical model to calculate the effect of the cost in $\$ / g$ of product under a number of different conditions. The effect of variations of the thermodynamic properties, the selectivity and the column saturation capacity, on the total cost reveal experimental work done up front to increase their values gives significant returns in lowering the cost. The effects of design parameters such as the maximum pressure and particle size are investigated showing that operation at higher pressure with smaller particles results in lower total cost. The economies of scale for chromatographic operation are investigated and show that the cost capacity curve has an exponent of 0.53 . Lastly, the effect of the cost of the crude on the optimum operating parameters is discussed showing that operation at high yields is important when the crude costs are high.
\end{abstract}

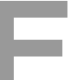
arly use of large scale low pressure chromatography came from developments in Manhattan Project and the fractionation of petroleum distillates and the separation of sugars [2-4]. The development of high performance process chromatography for industrial or manufacturing applications has steadily evolved over the last 10 years. The growth of the pharmaceutical industry and the need to develop and manufacture high purity bulk pharmaceutical products created a demand for the use of chromatography as a manufacturing unit operation [5-8]. The commercialization of large scale integrated equipment with pumps, columns and detectors and improved packing media, has provided an available supply of hardware to meet the demand [9-14]. Recently, the entry of many new manufacturers of columns, packing media, industrial detectors and automation software increased the selection of chromatography equipment. However, this also requires a greater understanding of the issues surrounding making choices of equipment and packing media.

The developments in the science of chromatography have brought to the literature many technical issues which could be used to improve the economics of chromatography as a unit operation. The development of mechanical strong packing media improves the media lifetime in compression systems by reducing or eliminating crushing which leads to higher pressure drop $[15,16]$. The understanding of the exis- tence of an optimum particle size squared over bed length which maximizes the production rate and understanding that separations with lower retention factors at constant separation factor have a greater throughput are important steps in development of the chromatographic process for manufacturing purposes $[17,18]$. Rules of thumb have been described to calculate the optimum value of $d_{\mathrm{p}}^{2} / L$ [19]. Methods have been developed for packing high efficiency axial compression columns [20-22]. Many advances have been made in understanding the science behind optimizing the operating conditions in isocratic elution, gradient elution and displacement chromatography [23-26]. The negative impact of large tubing volumes which degrade the separation have also been investigated [27]. Assessment of the economic factors for chromatographic unit operations have also been brought forward. For example, the identification of solvent costs as a large fraction of the total operating costs has brought on the development of recycle methodologies and further economic considerations regarding the choice of mobile phase $[28,29]$.

The discovery, development and use of chromatographic processes for manufacturing involve taking into account numerous issues. The discovery stage typically involves selection of a mobile phase and stationary phase system which meets a minimum performance requirement for the unit operation and for the process. The selection of a chromatographic solvent system typically takes into consideration compatibility with the previous and subsequent unit operation. Thus, the purpose of the discovery stage is to find a set of conditions to operate a chromatography column which performs the desired function of reducing the relevant impurities to sufficient levels and to take the product to a desired purity within a reasonable yield. The discovery stage is typically done on columns having internal diameters (ID) less than or equal to $1^{\prime \prime}$.

The development stage typically involves testing the process at an intermediate scale, 2" -6 " ID column, and investigating issues associated with solvent recycling, maximizing the loading, equipment selection and testing, packing lifetime evaluation, regeneration efficiency and understanding how the variability of the process influences it's performance. It is often difficult to insert into the development process formal optimization of the parameters for economic reasons. In chromatographic operations, the design parameters need to be selected carefully and the operating parameters need to be optimized in order to minimize the cost per unit mass of product produced. This paper shows how appropriate selection of design parameters and the optimization of operating parameters can significantly effect the total cost and the various cost components. Use of numerical calculations facilitates the accuracy and speed at which optimization is done. 


\section{Results and discussion}

The discovery, development and design of a chromatographic unit operation involves determination of both operating and design parameters for a given separation. For a given separation, the thermodynamic properties associated with the separation can be investigated and adjusted to reduce the cost of chromatographic operations. The optimization program used to make the calculations in this paper is described separately [28]. No solvent recycling is assumed. The assumptions for values of the parameters used in the optimization calculations for this work are summarized in table I. The calculation of cost is based on the contribution of system (installed equipment), labor, solvent, silica and lost crude. The cost values are based in 1993 dollars for an automated system and an axial compression column for all pressure ranges studied [30].

\section{The importance of thermodynamic properties}

The primary parameter which effects the economics of chromatography is the selectivity. Figure 1 illustrates the total cost in $\$ / g$ and the production rate versus the selectivity. A logarithmic reduction in total cost appears with increasing selectivity. An approximately linear increase in production rate is observed with increasing selectivity. Each data point along the $\$ / g$ curve is obtained by performing an optimization with an objective function of total cost $\$ / \mathrm{g}$ produced with the parameters, load amount, flow rate and column length. The total cost is calculated at each iteration of the optimization process from the cost parameters in table I and the operating and design conditions. This result shows that it is important to invest the resources up front to maximize the selectivity for a given problem to save on capital and operating costs during manufacturing. Table II shows the contributions to cost associated with the solvent, lost crude, labor, equipment, packing and the total cost in $\$ / \mathrm{g}$ as a function of the selectivity. These results show that the individual contributions to cost each reduce significantly with increasing separation factor. Table II shows that solvent costs are the largest contributor, regardless of the value of the selectivity.

The selectivity can be maximized by a screening process to facilitate making the most appropriate choice of the mobile phase composition (choice of organic modifier(s), and volume composition), stationary phase bonded moiety and bonding density, stationary phase endcapping, mobile phase buffer system, mobile phase $\mathrm{pH}$ and operating temperature, just to name a few. The experiments necessary to vary these parameters can be done easily with the automated analytical HPLC instrumentation and appropriate software.

The optimization of the operating parameters for minimum cost, once the thermodynamic conditions are workedout, provides significant value. There are an optimal amount loaded, flow rate and column length at each value of the selectivity, assuming all other parameters are held constant, including the pressure. This is illustrated in figure 2. Figure 2a shows that, as selectivity increases, the value of the opti-
Table I. Base case assumptions.

\begin{tabular}{|c|c|}
\hline Parameter & Value \\
\hline Maximum Operating Pressure & 60 bar \\
\hline Column Internal Diameter & $30 \mathrm{~cm}$ \\
\hline Nominal Particle Size & $16 \mu \mathrm{m}$ \\
\hline Void Fraction & 0.65 \\
\hline Bulk Packing Density & $0.6 \mathrm{~g} / \mathrm{cm}^{3}$ \\
\hline Time Cycle Factor & 2 \\
\hline Capacity Factor for 2nd component & 6 \\
\hline Selectivity & 1.2 \\
\hline Column Capacity Factor & $500 \mathrm{mg} / \mathrm{g}$ \\
\hline Crude Composition & $20: 80$ \\
\hline Final Purity & $98 \%$ \\
\hline Viscosity & $1.5 \mathrm{cP}$ \\
\hline Diffusion Coefficient & $10^{-6} \mathrm{~cm}^{2} / \mathrm{s}$ \\
\hline Knox Parameters & $A=1, B=2, C=0.05$ \\
\hline Depreciation & 10 yrs \\
\hline Equipment costs in 1993 & $\$ 600000$ \\
\hline Lang Factor for installation & 4 \\
\hline Methanol Cost & $\$ 0.35 / L$ \\
\hline Crude Cost & $\$ 1 / g$ \\
\hline Manpower Cost & $\$ 80$ 000/person \\
\hline Packing Cost & $\$ 4000 / \mathrm{kg}$ \\
\hline Packing Lifetime & 1000 hours \\
\hline \# Man-Persons & 2 persons/shift \\
\hline Shift Schedule & 3 shifts/day \\
\hline System Availability & 8400 hours/yr \\
\hline
\end{tabular}

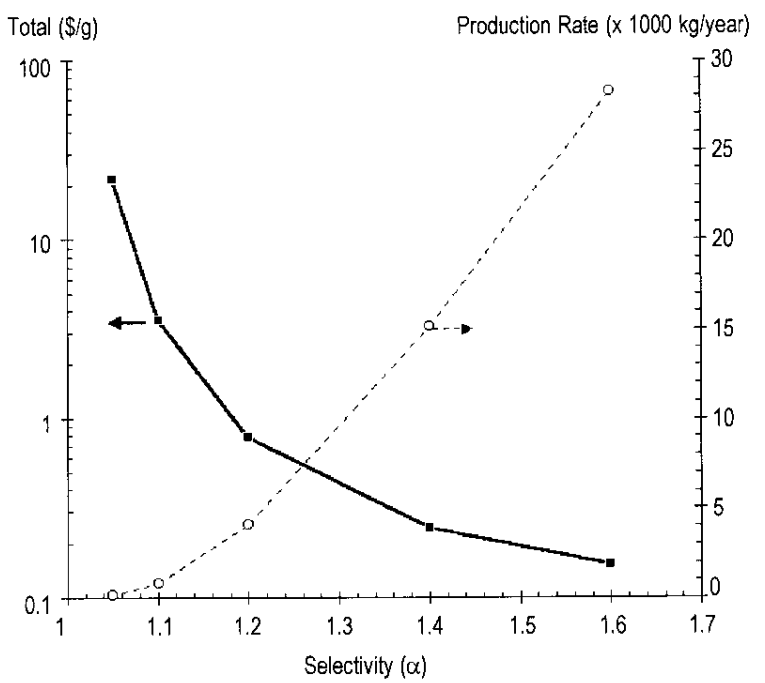

Figure 1. Plot of total cost $(\$ / g)$ and production rate versus selectivity, column saturation capacity $=500 \mathrm{mg} / \mathrm{g}$.

mum flow rate increases. Following the van Demter and Knox equations, this means that the required plate count decreases. Figure $2 b$ shows that with increasing selectivity, the amount loaded per gram of packing increases. Thus, the increase in production rate with increasing selectivity comes 
Table II. Effect of the separation factor on the contributions to total cost, $\$ / g$.

\begin{tabular}{|c|c|c|c|c|c|}
\hline \multicolumn{6}{|c|}{$\begin{array}{c}\text { (Pressure: } 60 \text { Bar, Internal Diameter: } 30 \mathrm{~cm} \text {, } \\
\text { Saturation Capacity: } 500 \mathrm{mg} / \mathrm{g} \text { ) }\end{array}$} \\
\hline$\$ / g$ & $\alpha=1.05$ & $\alpha=1.1$ & $\alpha=1.2$ & $\alpha=1.4$ & $\alpha=1.6$ \\
\hline Solvent & 5.2 & 1.1 & 0.32 & 0.14 & 0.093 \\
\hline Lost Crude & 1.7 & 0.29 & 0.10 & 0.018 & 0.018 \\
\hline Labor & 5.2 & 0.85 & 0.17 & 0.045 & 0.024 \\
\hline Equipment & 1.8 & 0.30 & 0.06 & 0.016 & 0.009 \\
\hline Packing & 7.9 & 1.0 & 0.14 & 0.022 & 0.010 \\
\hline Total & 21.9 & 3.5 & 0.79 & 0.24 & 0.15 \\
\hline
\end{tabular}
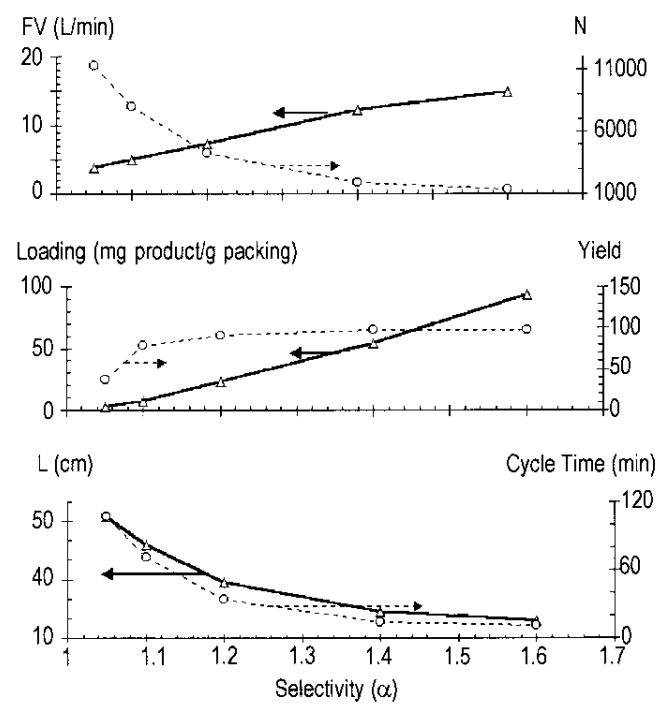

Figure 2. Plot of optimum value of the operating parameters versus selectivity. Column saturation capacity $=500 \mathrm{mg} / \mathrm{g}$. a) Flow rate and plate count versus selectivity, b) Loading and yield versus selectivity, c) Column length and cycle time versus selectivity.

in part from being able to load more product per run. Figure $2 \mathrm{~b}$ shows as well that the increased production rate with selectivity also comes in part from greater yields with increasing selectivity. Figure $2 \mathrm{c}$ shows that the optimum value for the column length decreases with increasing selectivity and thus the cycle time decreases with increasing selectivity. Therefore, with increasing selectivity the column length decreases as well as the required number of plates, thus allowing the flow rate to increase to meet the design pressure, resulting in significantly lower cycle time. Figure $2 \mathrm{c}$ also shows that the optimization of the column length contributes significantly to maximizing the production rate and thus reducing the total cost per gram of product, thus improving the economics of the process.

Figure 3 illustrates the elution profiles for a selectivity of 1.2 and 1.6 at different amounts loaded for binary mixtures of composition 1:3 and 3:1. Figure $3 a$ illustrates the chromatographic profile for a selectivity of 1.2 and a loading factor of 0.9 for the first component, and 2.8 for the second. a. $\alpha=1.2$

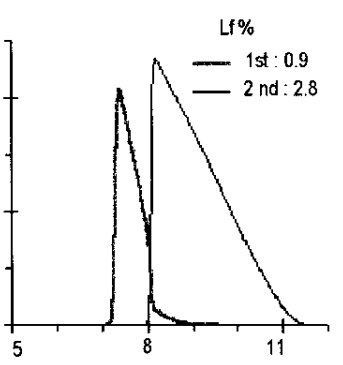

C.

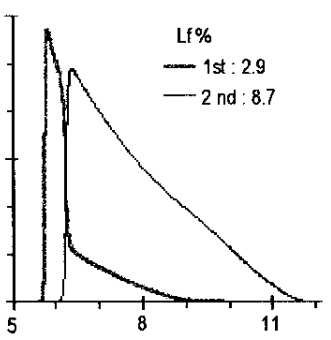

e.

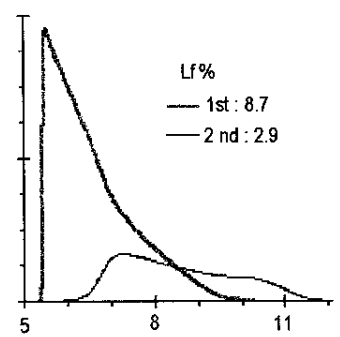

b. $\alpha=1.6$

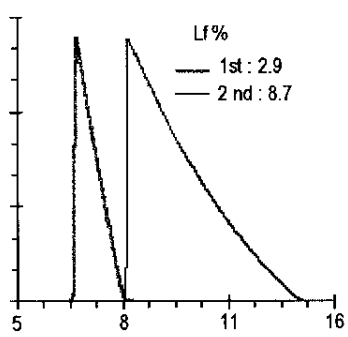

d.

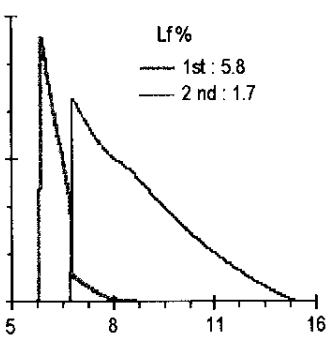

f.

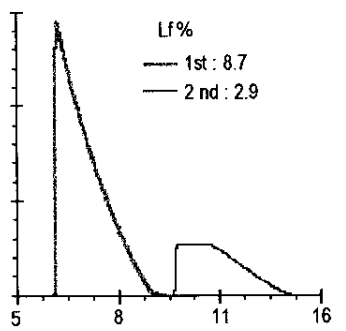

Figure 3. Plot of overloaded elution profiles at selectivity $=1.2$ and 1.6 for $1: 3$ and $3: 1$ mixtures. $b_{1}=0.0075, b_{2}=0.009, q_{\mathrm{s}, 1}=$ $q_{\mathrm{s}, 2}=3200, k_{1}^{\prime}=6, N=2000$, total porosity $=0.8, L=10 \mathrm{~cm}$, $F_{\mathrm{v}}=1 \mathrm{~mL} / \mathrm{min}, x: y=$ mixture composition, $L_{\mathrm{f}}=$ loading factor, a) $1: 3 L_{t}=0.9$ for $1^{\text {st }}$ component; 2.8 for $2^{\text {nd }}$ Component; $\mathbf{a}=1.2$, b) $1: 3 L_{f}=2.9$ for $1^{\text {st }}$ component; 8.7 for $2^{\text {nd }}$ Component; $a=1.6$, c) $1: 3 L_{\mathrm{f}}=2.9$ for $1^{\text {st }}$ component; 8.7 for $2^{\text {nd }}$ Component; $\mathrm{a}=1.2$, d) $1: 3 L_{\mathrm{f}}=5.8$ for $1^{\text {st }}$ component; 17 for $2^{\text {nd }}$ Component; $a=1.6$, e) $3: 1 L_{\mathrm{f}}=8.7$ for $1^{\text {st }}$ component; 2.9 for $2^{\text {nd }}$ Component; $\mathrm{a}=1.2$, f) $3: 1 L_{f}=8.7$ for $1^{\text {st }}$ component; 2.9 for $2^{\text {nd }}$ Component; $a=1.6$.

In this figure, the bands are slightly interfering. Figure $3 b$ shows that when the selectivity increases to 1.6 , the loading factor can be tripled and a touching band separation is obtained. Figure $3 \mathrm{c}$ illustrates the separation at the same loading as $3 \mathrm{~b}$, but for a selectivity of 1.2. Significant interference of the bands is observed and a yield loss would be required to obtain in high purity either the first or second component. Doubling the loading in figure $3 \mathrm{~b}$, for a selectivity of 1.6 shows slight interference is obtained. Figures $3 \mathrm{e}$ and $3 \mathrm{f}$ illustrate the band profiles of a 3:1 mixture at the same loading factor for selectivity values of 1.2 and 1.6; respectively. These chromatograms show that the second component exhibits a "tag-along" effect. One observes significantly improved separation at larger selectivity, which can be translated to higher production rates by increasing the amount loaded and reducing the distance between bands. 
The second thermodynamic property associated with Langmuir isotherms in chromatography is the column saturation capacity. The column saturation capacity is the maximum amount of a component required to cover all of the sites available on the stationary phase. Typical units of the column saturation capacity are mg or moles of compound per $\mathrm{mg}$ or $\mathrm{mL}$ of stationary phase. The column saturation capacity, as a direct measurement in itself, is more difficult than the selectivity; however, standard HPLC instrumentation can be used to make these measurements. Unlike for the measurements of the selectivity where mixtures are used, pure components are generally required for measurement of the column saturation capacity. One can use various isotherm measurement techniques, for example, Elution by Characteristic Point, Frontal Analysis or various retention time methods to determine the column saturation capacity [31]. Figure 4 illustrates how the total cost and production rate linearly increase with decreasing column saturation capacity. This figure shows that with increasing column saturation capacity, the packing costs, solvent costs and costs associated with labor decrease. The costs are plotted in a cumulative fashion, thus each contribution to cost is given by the distance between the lines. With increasing column saturation capacity, holding all other parameters constant, the load ratio increases from $4.5 \mathrm{mg} / \mathrm{g}$ to $9.0 \mathrm{mg} / \mathrm{g}$ as the column saturation capacity increases from $500 \mathrm{mg} / \mathrm{g}$ to $1000 \mathrm{mg} / \mathrm{g}$. Table III summarizes the assumptions for the calculations used to make figure 4 , which differ from the values in table I; as well as specific operating conditions and results. Use of temperature to optimize selectivity and column saturation capacity is an important element in the experimental component of the optimization process. For compounds where the column saturation capacity is low and the selectivity can be made large (for example enantiomers), it is important to consider carefully this trade-off.

\section{The effect of pressure}

In conjunction with selection of a mobile and stationary phase system to increase both selectivity and column saturation capacity, other design parameters can be selected. The column pressure rating is a design parameter that is selected or fixed depending on the maximum operating pressure, the difficulty of the separation, the type of equipment desired, the size of the equipment expected, the building space available, waste management and various safety issues. The design parameters particle size and column length as well as the operating parameter flow rate, each contributes to the pressure drop and thus must each be simultaneously optimized in order to evaluate the conditions which minimize total cost per unit mass produced. For example, use of larger particles lowers the pressure drop, but longer columns are required to meet the plate count requirement (which increases the pressure drop) and higher flow rates are needed to minimize the cycle time. The particle size has a relationship to its square with the pressure drop while the flow rate and the column length have a linear relationship with pressure drop. The trade-off with the column length, particle size, flow rate and amount loaded is the fundamental multicomponent optimization problem in chromatography which needs to be addressed in order to minimize total costs per unit mass of product produced.
Table III. Effect of saturation capacity constants and operating parameters.

\begin{tabular}{lc}
\hline Parameter & Value \\
\hline Purity & $95 \%$ \\
Capacity Factor for 2nd component & 5.25 \\
Selectivity & 1.05 \\
Length, cm & 72.7 \\
Flow rate, $\mathrm{mL} / \mathrm{min}$ & 3.88 \\
Linear Velocity, cm/min & 0.329 \\
Cycle Time, min & 107.5 \\
Number of Plates & 11240 \\
Yield & 62.1 \\
kg Packing & 30.8 \\
\hline
\end{tabular}

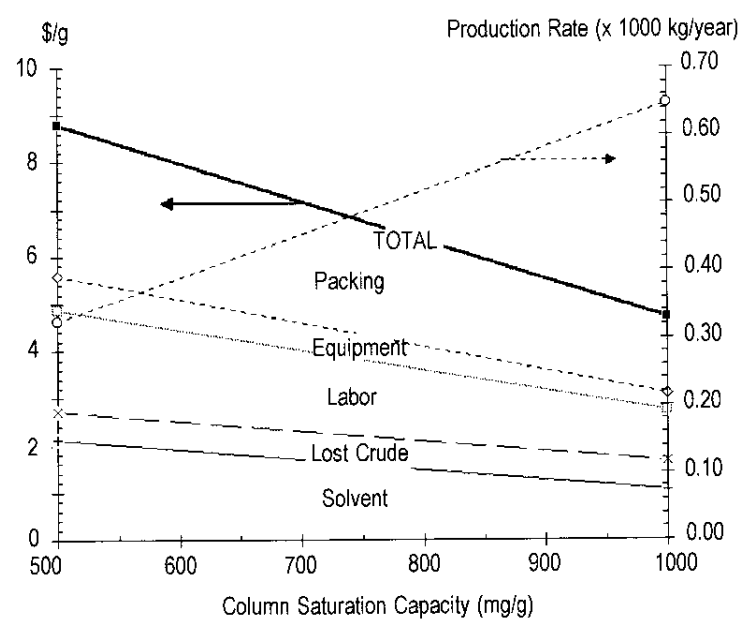

Figure 4. Plot of total cost $(\$ / g)$ and production rate versus column saturation capacity. Selectivity $=1.05$.

Part of selecting the design pressure is investigating the issues around pressure and pressure rating. The system pressure rating takes into account the maximum operating pressure primarily associated with the pressure drop across the column. In chromatographic systems, the pressure drop across the column is a function of the flow rate, of the load and mobile phase through the packed bed, the viscosity of the load, the viscosity of the mobile phase, the mean particle size, the particle size distribution and shape, and the column length. In addition to taking into account the operating pressure and pressure rating of the column, it is also necessary to account or design appropriately for the pressure rating of other equipment (e.g. filters, valves, etc.), the pressure rating of the pump and piping, the levels of safety required to protect the equipment and the operators, and lastly the non-quantifyable variables associated with packing lifetime such as increased pressure over time due to crushing of the packing, formation of fines, irreversible adsorption etc. Typically, the maximum allowable operating pressure is less than $90 \%$ of the design pressure rating of the limiting piece of equipment to ensure safe practices. 
The effect of pressure on the cost in \$/g and the production rate for a given set of conditions is illustrated in figure 5 . This figure shows that operation at higher pressure results in higher production rates and lower costs. The cost components are graphically illustrated in a cumulative manner and labeled accordingly. This result shows that as the pressure increases the labor costs decrease. This comes out of the assumption that the number of operators needed is not a function of the size of the equipment.

Figure 6 shows how the optimum value of the operating parameters vary with increasing pressure. Figure 6a illustrates that with increasing pressure, the optimum value for the flow rate increases. This figure also shows that with increasing pressure the value of the required plate count increases. Figure $6 \mathrm{~b}$ illustrates that the amount loaded per $g$ of packing is relatively constant with increasing pressure and the yield increases with increasing pressure. Figure $6 \mathrm{c}$ illustrates that the optimal value of the column length increases with increasing pressure drop. This means that with increasing pressure the amount of product loaded increases because the amount of packing increases with increasing column length. Note that the net effect of increased column length and increasing flow rate is a higher plate count. The optimal value of the cycle time is relatively constant at high pressure but increases with increasing pressure in the low pressure range. Thus, the production rate increases with increasing pressure because the yield increases due to the higher number of plates and because the amount loaded increase comes from having longer columns and more separation capacity.

Figures $7 \mathrm{a}$ and $7 \mathrm{~b}$ illustrate the chromatographic elution profiles at an operating pressure of 10 bar and 200 bar, respectively; corresponding to the conditions of minimum total cost. The chromatographic profiles at the two pressures are similar. At the higher pressure, the elution profiles elute several minutes later. A summary of the operating parameter values are in table IV. These conditions are different from previous figures (note in particular a much lower column saturation capacity: $75 \mathrm{mg} / \mathrm{g}$ ). These results show operating at higher pressure results in the use of longer columns, having a higher number of plates, and operated at higher flow rates. However, the cycle time remains essentially unchanged. The amount loaded, yield and flow rate balance the lost crude costs and the solvent costs. The total cost and contributions due to packing, solvent, lost crude, labor and equipment are summarized in table V. The primary sources of savings for operating at higher pressure come from the increased amount loaded, and thus increased throughput and yield. This results in lower labor and lost crude costs. At the higher pressure and considering the assumptions made, the total cost is $\$ 0.66 / \mathrm{g}$ while at the lower pressure it is $\$ 1.19 / \mathrm{g}$ (see Tab. V).

\section{Economies of scale}

As with most unit operations, chromatography also has economies of scale. Figure 8 illustrates the cost per gram and the production rate as a function of the column internal diameter for a somewhat difficult separation (selectivity of 1.2 ) and a column saturation capacity of $500 \mathrm{mg} / \mathrm{g}$. Typical equipment costs for columns having an internal diameter of

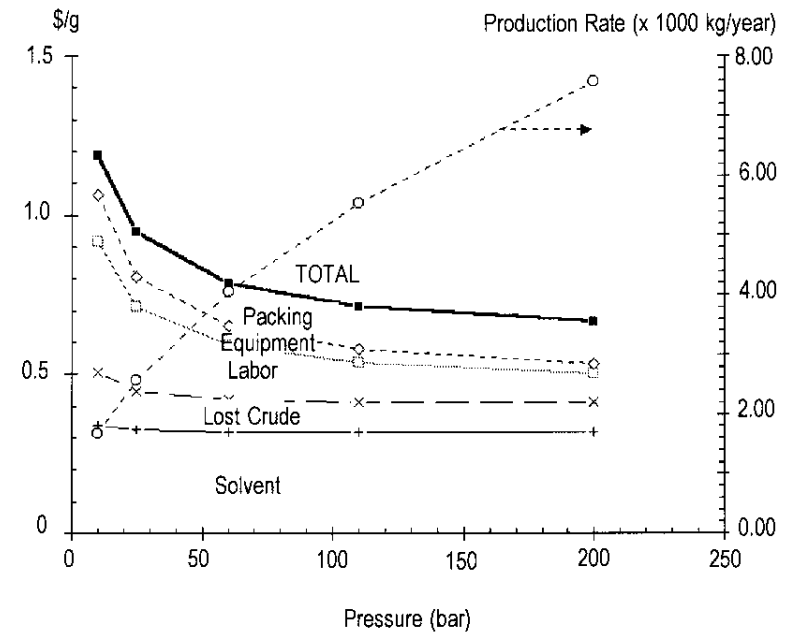

Figure 5. Plot of total cost $(\$ / g)$ and production rate versus the column pressure. Selectivity $=1.2$; saturation capacity $=$ $500 \mathrm{mg} / \mathrm{g}$.

a.

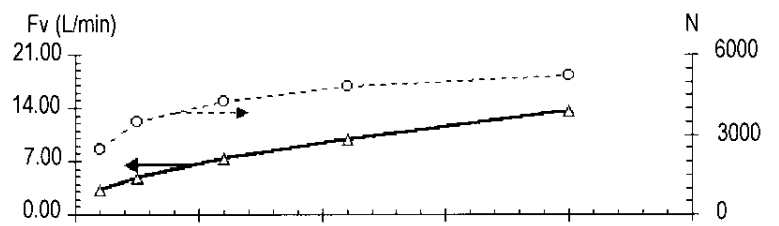

b.

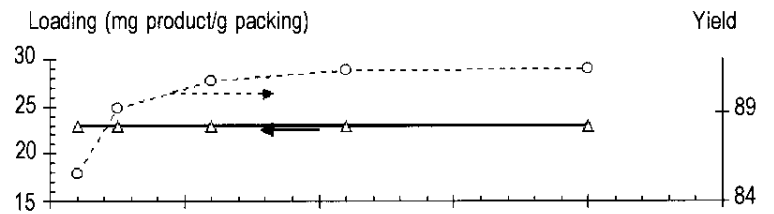

C.

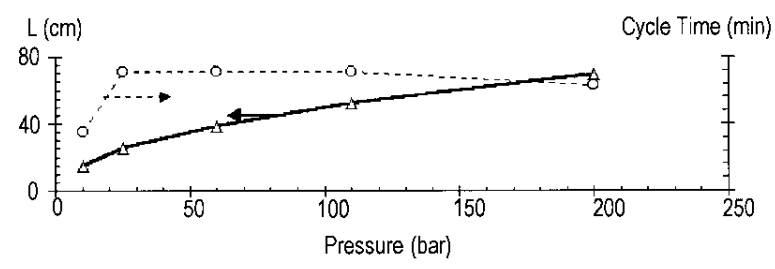

Figure 6. Plot of optimum value of the operating parameters versus column pressure. Selectivity $=1.2$; saturation capacity $=500$ $\mathrm{mg} / \mathrm{g}$. a) Flow rate and plate count versus pressure, b) Loading and yield versus pressure, c) Column length and cycle time ver sus pressure.

$15 \mathrm{~cm}, 30 \mathrm{~cm}, 60 \mathrm{~cm}$ and $80 \mathrm{~cm}$ are $\$ 120000, \$ 240000$, $\$ 480000$ and $\$ 690000$ with a Lang factor of 4 for installation. With increasing scale, costs are reduced primarily due to lower labor, lost crude costs and system costs with packing costs increasing slightly and solvent costs remaining constant. For these conditions and in order of decreasing contribution, labor, solvent and lost crude costs are significant contributors to the total cost for small ID columns. The solvent, packing and lost crude costs are the significant contributors for larger ID columns. This result suggests investment into longer life packing when the scale of 
a.

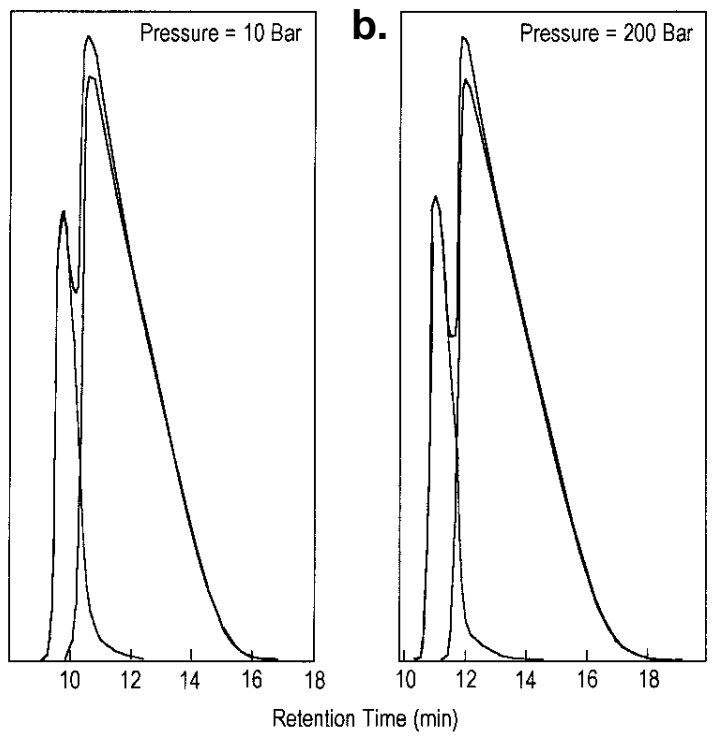

Figure 7. Plot of overloaded elution profiles at 10 bar and 200 bar. Selectivity $=1.1$; saturation capacity $=75 \mathrm{mg} / \mathrm{g}$. a) 10 bar, b) $\mathbf{2 0 0}$ bar.

Table IV. Summary of operating and design parameters.

\begin{tabular}{lcc}
\hline Parameter & 10 Bar & 200 Bar \\
\hline Bed Length, cm & 14.7 & 69.3 \\
Flow Rate, L/min & 3.2 & 13.6 \\
Cycle Time, min & 29.4 & 32.8 \\
Throughput, 1000kg/year & 1.6 & 7.5 \\
Number of Plates & 2482 & 5245 \\
Reduced Plate Height & 3.7 & 8.3 \\
Effective Plates & 609 & 890 \\
Loading mg/g & 22.9 & 22.9 \\
Amount Loaded, g & 143 & 674 \\
Yield, \% & 85.5 & 91.5 \\
Amount of Packing, kg & 6.2 & 29 \\
\end{tabular}

Table V. Summary of costs as a function of pressure.

\begin{tabular}{lll}
\hline Parameter & 10 Bar & 200 Bar \\
\hline Packing, $\$ / g$ & 0.13 & 0.13 \\
Solvent, $\$ / g$ & 0.34 & 0.31 \\
Lost Crude, $\$ / g$ & 0.17 & 0.09 \\
Labor, $\$ / g$ & 0.41 & 0.09 \\
Equipment, $\$ / g$ & 0.14 & 0.13 \\
Total, $\$ / g$ & 1.19 & 0.66 \\
\hline
\end{tabular}

manufacturing goes beyond $15 \mathrm{~cm}$ internal diameter columns becomes a worthwhile activity in minimizing costs.

Figure 9 illustrates the total cost per gram and the production rate curves at 20 bar and 60 bar for a fairly difficult separation (selectivity of 1.1) and a column saturation capacity of $75 \mathrm{mg} / \mathrm{g}$. The assumptions for the calculations

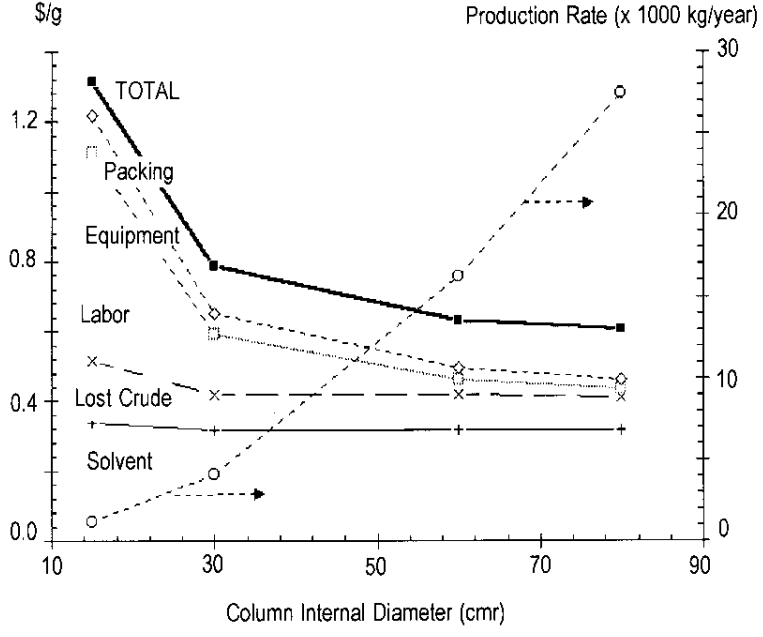

Figure 8. Plot of total cost and production rate versus column internal diameter. Selectivity $=1.2$; saturation capacity = $500 \mathrm{mg} / \mathrm{g}$; pressure = 60 bar.

Table VI. Base case assumptions for pressure drop vs. column ID graph.

\begin{tabular}{lc}
\hline Parameter & Value \\
\hline Maximum Operating Pressure & $20 / 60 \mathrm{bar}$ \\
Column ID & $15 \mathrm{~cm}$ \\
Nominal Particle Size & $16 \mu \mathrm{m}$ \\
Void Fraction & 0.65 \\
Bulk Packing Density & $0.6 \mathrm{~g} / \mathrm{cm}^{3}$ \\
Time Cycle Factor & 4 \\
Capacity Factor for 2nd component & 8 \\
Selectivity & 1.1 \\
Column Capacity Factor & $75 \mathrm{mg} / \mathrm{g}$ \\
Crude Composition & $90: 10$ \\
Final Purity & $98 \%$ \\
Viscosity & $1.2 \mathrm{Cp}$ \\
Diffusivity & $10^{-6} \mathrm{~cm} / \mathrm{s}$ \\
Knox Parameters & $B=2, \mathrm{C}=0.05$ \\
Depreciation & $10 \mathrm{yrs}$ \\
Equipment costs in 1993 & $\$ 300 \mathrm{000}$ \\
Lang Factor for installation & 4 \\
Methanol Cost & $\$ 0.35 / \mathrm{L}$ \\
Crude Cost & $\$ 1000 / \mathrm{g}$ \\
Manpower Cost & $\$ 80000 / \mathrm{person}$ \\
Packing Cost & $\$ 4000 / \mathrm{kg}$ \\
Packing Lifetime & $1000 \mathrm{hours}$ \\
\# Man-Persons & $2 \mathrm{persons} / \mathrm{shift}$ \\
Shift Schedule & $3 \mathrm{shifts} / \mathrm{day}$ \\
System Availability & $8400 \mathrm{hours} / \mathrm{yr}$ \\
\hline &
\end{tabular}

for this figure are provided in table VI. Figure 9 shows how operating at higher pressure reduces the total cost/gram and increases the production rate over the entire range of 


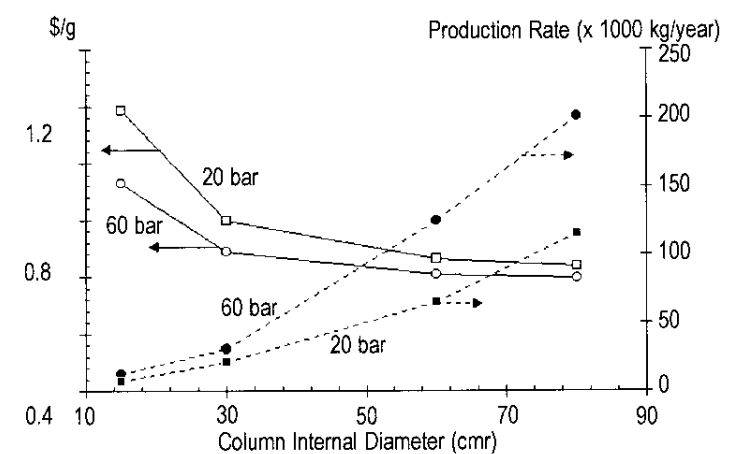

Figure 9. Plot of total cost and production rate versus column internal diameter. Selectivity $=1.1$; saturation capacity = $75 \mathrm{mg} / \mathrm{g}$; pressure $=20$ and 60 bars.

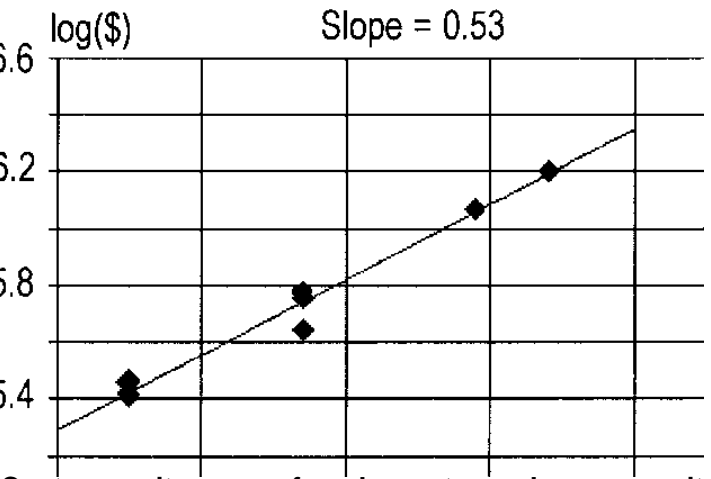

Figure 10. Cost capacity curve for chromatography as a unit operation.

column internal diameter. This figure also shows that in some cases one can use a larger diameter column at a lower pressure drop and get a similar value for the cost per unit mass at the same production rate. Tables VII and VIII summarize the contribution to each cost component. Similar to the easier separation in figure 8 , the economy of scale comes from decreasing lost crude, labor and system costs with scale.

Figure 10 illustrates the cost-capacity factor curve. The different points associated with each column internal diameter (or cross section) takes into account prices from different equipment suppliers. The exponential factor is the slope of this log-log plot. In the advent of limited information, an exponent of 0.6 is often used to ascertain cost associated with increasing scale for chemical process equipment [32]. In chromatography this factor has been estimated at 0.53 , which suggests significant reductions in cost with scale are observed. This result suggests the economies of scale may be greater in many circumstances with chromatography compared to other processes.

\section{Particle size}

The particle size is another design parameter which needs to be selected to minimize costs. Figure 11 illustrates how the cost per gram and the production rate vary with increasing

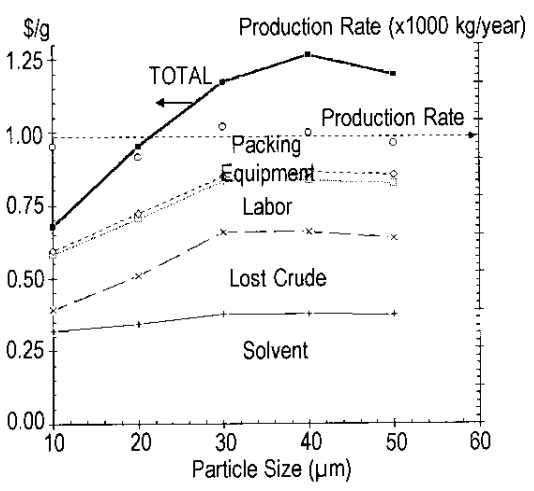

Figure 11. Plot of total cost and production rate versus particle size. Selectivity $=1.2$; saturation capacity $=500 \mathrm{mg} / \mathrm{g}$.
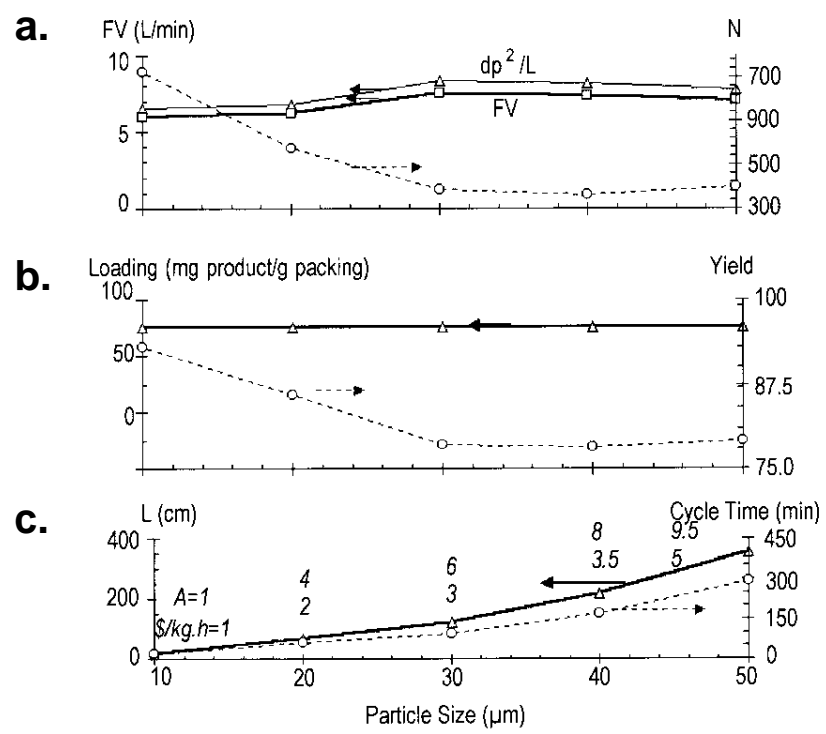

Figure 12. Plot of optimum value of operating parameters ver sus particle size selectivity $=1.2$; saturation capacity $=$ $500 \mathrm{mg} / \mathrm{g}$. a) Flow rate and plate count versus particle size, b) Loading and yield versus particle size, c) Column length and cycle time versus particle size.

particle size. The cumulative contributions are indicated by each line, with the individual cost contributions, labeled accordingly, as the distance between the lines. As the particle size increases, the total cost per gram of product produced increases (on the contrary to a common believe), the production rate being constant. There is an optimum value of the $d_{\mathrm{p}}^{2} / L$ ratio. This graph also shows that the lost crude costs and packing costs increase with increasing particle size. These two factors are the primary contributing cost components with increasing particle size. The cycle time decreases with decreasing particle size and this poses limitations with regards to the time it realistically takes to operate the equipment and software.

The optimum values for the operating parameters as a function of particle size are illustrated in figure 12. Figure $12 \mathrm{a}$ shows that the ratio $d_{\mathrm{p}}^{2} / L$ is constant. The flow rate is essential constant and the number of plates decreases with 
Table VII. Cost summary for various column internal diameters at 20 Bar.

\begin{tabular}{lcccc}
\hline \multicolumn{5}{c}{ (20 Bar Pressure, $\left.\alpha=1.1, Q_{s}=75 \mathrm{mg} / \mathrm{g}{ }^{(1)}\right)$} \\
Diameter & $15 \mathrm{~cm}$ & $30 \mathrm{~cm}$ & $60 \mathrm{~cm}$ & $80 \mathrm{~cm}$ \\
\cline { 5 - 5 } Solvent & 16 & 23 & 29 & 29 \\
Lost Crude & 98 & 53 & 32 & 32 \\
Labor & 95 & 33 & 11 & 6 \\
System & 16 & 12 & 7 & 6 \\
Packing & 21 & 29 & 37 & 37 \\
Total \$/g & $\mathbf{2 4 6}$ & $\mathbf{1 5 0}$ & $\mathbf{1 1 6}$ & $\mathbf{1 1 0}$ \\
\hline
\end{tabular}

${ }^{(1)} \alpha$ : Selectivity. $Q_{S}$ : Saturation capacity.

Table VIII. Cost summary for various column internal diameters at 60 Bar.

\begin{tabular}{|c|c|c|c|c|}
\hline \multicolumn{5}{|c|}{ (60 Bar Pressure, $\left.\alpha=1.1, Q_{s}=75 \mathrm{mg} / \mathrm{g}\right)$} \\
\hline Diameter & $15 \mathrm{~cm}$ & $30 \mathrm{~cm}$ & $60 \mathrm{~cm}$ & $80 \mathrm{~cm}$ \\
\hline Solvent & 19 & 29 & 29 & 29 \\
\hline Lost Crude & 75 & 32 & 32 & 26 \\
\hline Labor & 57 & 22 & 6 & 3 \\
\hline System & 10 & 8 & 4 & 3 \\
\hline Packing & 21 & 32 & 32 & 37 \\
\hline Total $\$ / g$ & 182 & 123 & 102 & 99 \\
\hline
\end{tabular}

increasing particle size. Figure $12 \mathrm{~b}$ shows the yield decreases with increasing particle size (a consequence of the lower number of plates) while the amount loaded per unit mass of packing media remains essentially constant. Figure $12 \mathrm{c}$ shows that the column length and cycle time increase with increasing particle size. In order to make these calculations, the values of the A parameter of the Knox equation were based on experimental data from Eka Chemicals and the price of packing was varied based on various vendor prices. The values for the $\$ / \mathrm{kg} . \mathrm{hr}$ was adjusted to decreasing packing costs with increasing particle size while maintaining the lifetime constant $(\$ 5 / \mathrm{g}, 10 \mu \mathrm{m} ; \$ 4 / \mathrm{g}, 16 \mu \mathrm{m}$; $\$ 3.5 / \mathrm{g}, 20 \mu \mathrm{m} ; \$ 3 / \mathrm{g}, 30 \mu \mathrm{m} ; \$ 2 / \mathrm{g}, 40 \mu \mathrm{m} ; \$ 1 / \mathrm{g}, 50 \mu \mathrm{m})$. Figure $12 \mathrm{c}$ shows the $A$ factor value and $\$ / \mathrm{kg}$.hr assumptions with particle size.

\section{Effect of crude costs}

Lastly, the impact of the crude cost on the separation influences greatly the operating conditions. Figure 13 illustrates how the total cost increases with increasing crude cost. The assumptions for the calculations of these figures are given in table I. Packing, labor and to some extent equipment costs increase with increasing crude costs. The production rate decreases with increasing crude costs. Figure 14 illustrates how the optimum operating conditions vary with increasing crude costs. Figure 14a shows how the flow rate decreases and thus the required plate count increases with increasing crude cost. Figure $14 \mathrm{~b}$ shows that the amount loaded per unit mass of packing decreases and the yield increases with

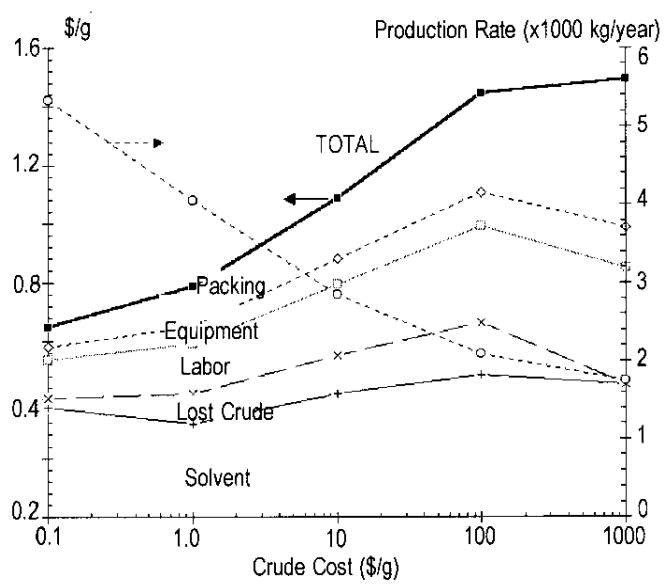

Figure 13. Plot of total cost and production rate versus crude cost. Selectivity = 1.2; saturation capacity $=500 \mathrm{mg} / \mathrm{g}$.
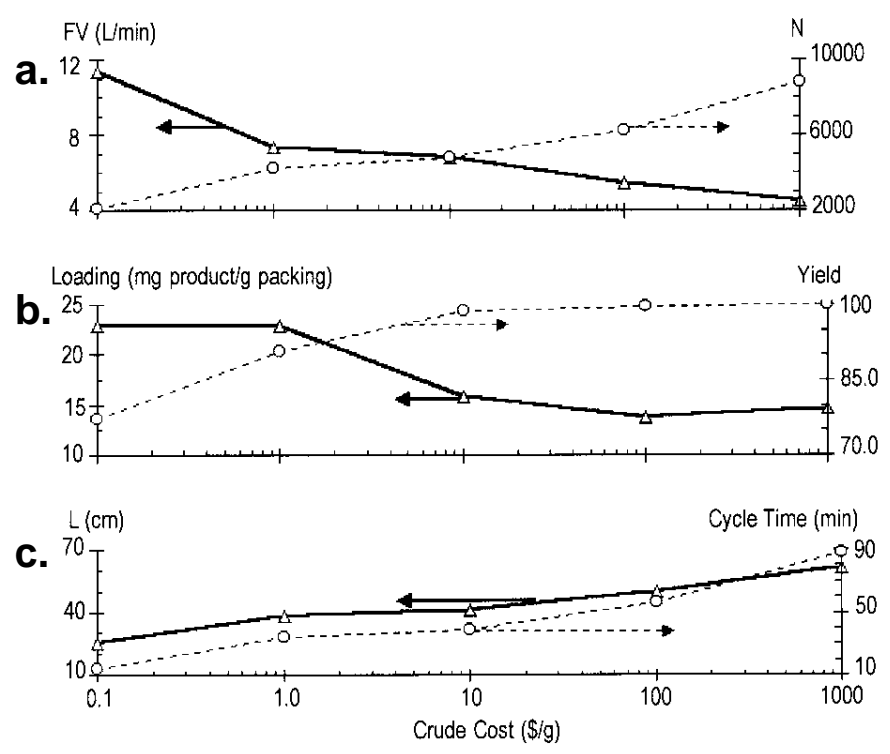

Figure 14. Plot of the optimum value of operating parameters versus crude cost $\$ / \mathrm{g}$. Selectivity = 1.2; saturation capacity = $500 \mathrm{mg} / \mathrm{g}$. a) Flow rate and plate count versus crude cost, b) Loading and yield versus crude cost, c) Column length and cycle time versus crude cost.

increasing crude costs. Figure $14 \mathrm{c}$ shows that the column length and the cycle time increase with increasing crude costs. The optimization process for minimum total cost per unit mass says if lost crude costs dominate, it is necessary to minimize the total cost per unit mass produced. In order to minimize the lost crude cost, the yield needs to increase. In order to increase the yield, the number of plates required increases, so the column length increases and the flow decreases. Thus the cycle time increases and the production rate decreases.

\section{Conclusions}

In order to improve the economics of chromatographic unit operations, the experimental conditions need to be studied 
in the laboratory to maximize the selectivity and the column capacity factor. In addition, the design parameters pressure drop, column length and particle size and the operating parameter flow rate need to be optimized simultaneously to reduce the initial capital costs and the operating costs.

\section{References}

1. Author to whom correspondence is directed.

2. Spedding, F. H.; Voight, A. F.; Gladrow, E. M.; Sleight, N. R.; Powel, J. E.; Wright, J. M.; Butler, T. A.; Figard, P. J. Am. Chem. Soc. 1947, 69, 2786.

3. Mair, B. J.; Gaboriault, A. L.; Rossini, F. D. Ind. Eng. Chem. 1947, 39, 1072.

4. Broughton, D. B. Separat. Sci. Technol. 1984, 19, 723.

5. Dwyer, J. Biotechnology, Nov. 1984; p 957-964.

6. Nicoud, R. M.; Fuchs, G.; Adam, P.; Bailly, M.; Kusters, E.; Antia, F.; Reuille, R.; Schmid, E. Chirality 1993, 5, 267-271.

7. Cantwell, A. M.; Calderone, R.; Sienko, M. J. Chromatogr. 1986, 363, 31-36.

8. Kroeff, E.; Owens, R.; Campbell, E.; Johnson, R.; Marks, H. J. Chromatography 1989, 461, 45-61.

9. Skea, W. M. Chem. Anal. 1987, 98, 479-527.

10. Godbille, E.; Tondu, L., US Patent 3, 966, 609.

11. Mc Donald, P.; Rausch, W., US Patent 4, 250, 035.

12. Colin, H.; Hilaireau, P.; de Tournemire, J. "Dynamic Axial Compression Columns for Preparative High Performance Liquid Chromatography", Vol. 8, No. 4.

13. Mann, G. Reflections on Packing Media, PREP'95, Georgetown Uni versity, Washington DC.

14. Subramanian, G. "Preparative and Process-Scale Liquid Chromatography", Ellis Horwood, New York, 1991.

15. Sarker, M.; Katti, A.; Guiochon, G. J. Chromatogr. A 1996, 719, 275-289.
16. Guan, H.; Guiochon, G.; Coffey, D.; El David; Gulakowski, K.; Smith, D. J. Chromatogr. A 1996, 736, 21-30.

17. Golshan-Shirazi, S.; Guiochon, G. Anal. Chem. 1989, 61, 1368.

18. Felinger, A.; Guiochon, G. J. Chromatogr. 1992, 591, 31-45.

19. Golshan-Shirazi, S.; Guiochon, G. American Biotechnology Laboratory, June 1990, p 26-34.

20. Sarker, M.; Guiochon, G. $L C / G C$ 1994, 12, 300-306.

21. Wu, D. -R.; Lohse, K. J. Chromatogr. A 1994, 658, 381-389.

22. Colin, H.; Hilaireau, P.; de Tournemire, J. $L C / G C$ 1990, 8(4), 301-312.

23. Felinger, A.; Guiochon, G. AICHE J. 1994, 40, 594-605.

24. Felinger, A.; Guiochon, G. J. Chromatogr. A 1996, 724, 27.

25. Felinger, A.; Guiochon, G. J. Chromato gr. A 1998, 796, 59.

26. Felinger, A.; Jacobson, S.; Guiochon, G. Biotechnology/ Bioengineering 1992, 40, 1210.

27. Guiochon, G.; Golshan-Shirazi, S.; Katti, A. "Fundamentals of Preparative and Nonlinear Chromatography", Academic Press, 1994; p 653.

28. Colin, H. In: "Preparative and Production Scale Chromatography", G. Ganetsos and P. E. Barker Eds., Volume 61 Marcel Dekker, Inc. New York, 1993; p 11-45.

29. Jageland, P.; Magnusson, J.; Bryntesson, M. J. Chromatogr. A 1994, 658, 497-504.

30. Katti, A.; Jageland, P. "Cost Analysis in the Optimization of Preparative Chromatography", International Conference on Preparative Chromatography, Washington D.C., June 11-14, 1995.

31. Guiochon, G.; Golshan-Shirazi, S.; Katti, A. "Fundamentals of Preparative and Nonlinear Chromatography", Academic Press, 1994; p 80-96.

32. Peters, M. S.; Timmerhaus, K. D. Plant Design and Economics for Chemical Engineers, $3^{\text {rd }}$ ed., McGraw-Hill Book Co., NY 1980; p 167. 